\title{
O PROCESSO DE (IN)DEPENDÊNCIA DO ADULTO JOVEM
}

\author{
Maria Lucia de Souza Campos Paiva ${ }^{1}$
}

\section{Resumo}

$\mathrm{Na}$ atualidade, muitos adultos jovens prolongam sua permanência na casa de seus familiares. São inúmeras as razões que podem explicar tal fenômeno. O presente artigo aborda a questão com base no desenvolvimento emocional da independência do sujeito e como a educação pode propiciar, no âmbito familiar, o surgimento de um sujeito autônomo e independente na vida adulta.

Palavras-chave: Adulto Jovem. Família. Relações familiares. Autonomia.

\section{THE PROCESS OF (IN)DEPENDENCE OF THE YOUNG ADULT}

\begin{abstract}
Nowadays, many young adults extend their stay in the family house. There are countless reasons that can explain this phenomenon. This article addresses the issue from the emotional development of the subject's independence and how education can provide, within the family, the emergence of an autonomous and independent subject in adult life.
\end{abstract}

Keywords: Young Adult. Family. Family relationships. Autonomy.

\section{Introdução}

A questão do desenvolvimento da autonomia, entre os jovens permeia as discussões tanto nos meios universitários, junto aos profissionais ligados à educação, à psicologia, à sociologia, como nos debates familiares. Um aspecto central em tais reflexões seria a questão de como educar as crianças e os jovens para que se tornem adultos autônomos e responsáveis. É possível encontrar adultos jovens, apresentando dificuldades de se desvincular da família de origem e em assumir um projeto de vida pessoal. Em classes sociais mais altas, alguns estudantes prolongam seu curso universitário em mais anos do que os propostos pelas universidades, sem se preocuparem quando assumirão o próprio sustento financeiro. Uma das justificativas é que não gostariam de se sentirem pressionados a estudar tantas horas/aulas por semestre, seguindo o cronograma sugerido pela instituição de ensino. Usufruem da possibilidade de cumprirem menos créditos por semestre com o intuito de terem outras experiências nessa fase de sua vida, uma vez que no Ensino Médio se sentiram privados de tal possibilidade.

Outrora, a falta de liberdade sexual e de privacidade impulsionava os jovens a buscarem seus próprios espaços longe da família que os criou, chegando alguns deles até a casarem cedo para adquirirem a almejada liberdade. Entretanto, com os limites mais frouxos, naquilo que era em outras épocas intolerável e impensável, os jovens acabaram

\footnotetext{
${ }^{1}$ Pedagoga, psicóloga clínica, psicanalista, doutora em Psicologia Clínica do Instituto de Psicologia da Universidade de São Paulo.
} 
trazendo a vida sexual para dentro de sua casa, convivendo "ficantes" e namorados com a família de origem.

Postergando a saída da casa de seus pais/mães ou morando em outros espaços, divididos com outros jovens, nas ditas repúblicas, muitos desses adultos jovens apresentam comportamentos ainda imaturos para a faixa etária, necessitando tanto apoio emocional como de ajuda financeira de seus pais. Quais seriam as razões que levariam esses jovens adultos a permanecerem tão vinculados aos seus cuidadores?

Na contemporaneidade, há diversas configurações familiares, as heteroparentais, as homoparentais, as monoparentais e as famílias recompostas, que se organizam com base em um casamento anterior de um ou dos dois adultos que exercem a função parental. Em todos esses modelos de família, é possível dizer que existem jovens que prolongam sua moradia na casa de seus pais por muitos anos, não se podendo dizer que um desses modelos induz a tal situação.

Em 2004, o fenômeno já era apontado em uma reportagem da revista Época, em que a jornalista Martha Mendonça apontava que o fato de os filhos não saírem da casa dos pais era um fato mundial, não apenas brasileiro. Na Itália, era conhecido como mammismo e apresentava algumas características marcantes. Os jovens do sexo masculino aceitavam que a mãe interferisse até na escolha das namoradas. Em uma pesquisa realizada na época dessa reportagem, nesse mesmo país, foi obtido como dado que $71 \%$ dos jovens admitiram que é desnecessário viver por conta própria. Já em Portugal e na Espanha, a família era vista como um refúgio das crises sociais. Nesses países, apenas $4 \%$ da população de adultos moravam separado dos pais.

Nos Estados Unidos, essa dinâmica parecia ser menor, mesmo assim chamava a atenção. Apelidada como geração bumerangue, os jovens saíam de casa para estudar em outros estados, mas a grande maioria acabava retornando à casa dos pais. No Brasil, mais precisamente no Rio de Janeiro, 29\% dos adultos com mais de trinta anos ainda moravam, na época, com os pais.

Mais de dez anos depois, o fenômeno continua bastante frequente entre os jovens que, mesmo tendo algum tipo de renda própria, moram ainda com seus pais ou mães. Em outra reportagem, desta vez do El Pais, a jornalista Heloisa Mendonça (2017) comenta que um quarto dos jovens - de vinte e cinco a trinta e quatro anos - ainda mora com a família de origem. Afirma que era menor essa proporção doze anos antes, quando um quinto deles morava com os pais.

Segundo a escritora, a "geração canguru", como foi apelidada, tem várias razões que justificam ainda estarem presos às famílias; entre elas, os estudos prolongados, o alto custo de vida e fatores econômicos, além de fatores emocionais.

Em uma tentativa de satirizar o que é vivido pelos adultos jovens, o grupo de comediantes "Porta dos Fundos" lançou, em 2018, o episódio "Morando Sozinho". Já na cena inicial, aparece um adulto jovem, aparentando seus trinta e poucos anos, abrindo a porta do apartamento para um profissional que faz pequenos reparos, um "faz tudo". O morador vai logo explicando que precisa de ajuda, já que é a primeira vez que mora sozinho e desconhece como funcionam "essas coisas de apartamento". Compara a pia de 
seu apartamento com a pia da casa de sua mãe: abre a torneira, a água bate nos pratos e eles continuam sujos, já na casa de sua mãe existe uma pia que funciona direito: em quinze minutos tudo está lavado.

A dinâmica familiar e o processo educacional nos primeiros anos da infância assumem um peso enorme na permanência dos filhos por tempo indeterminado na casa de quem os criou. A singularidade de cada núcleo familiar torna difícil fazermos generalizações, mas alguns apontamentos são possíveis com base no entendimento do desenvolvimento da independência e da autonomia do sujeito psíquico.

\section{Desenvolvimento da independência}

A questão do vínculo entre pais/mães e seus filhos que se apresenta pode ser entendida por vários ângulos. Inicialmente, seria importante entender como se dá o processo de desenvolvimento da autonomia no sujeito, para posteriormente se pensar em algumas hipóteses que explicariam esse prolongamento da permanência dos filhos na casa dos pais.

Winnicott (1963) descreveu o desenvolvimento emocional do indivíduo, em relação ao processo de dependência/independência. Segundo esse autor, o adulto nunca se torna independente completamente. Não é possível pensar em um indivíduo isolado, que não esteja relacionado a um ambiente. Pode-se dizer que indivíduo e ambiente estão interligados.

Esse autor propôs três categorias para se pensar a respeito do desenvolvimento da independência no adulto. A primeira categoria seria a dependência absoluta, depois, a dependência relativa e a última categoria seria rumo à independência.

A dependência absoluta começa nos estágios iniciais do desenvolvimento da criança. $\mathrm{O}$ bebê é totalmente dependente dos cuidados maternos. "Podemos dizer que o ambiente favorável torna possível o progresso continuado dos processos de maturação." (WINNICOTT, 1963, p.81), mas esse ambiente não define a criança, ele apenas ajuda a desenvolver suas potencialidades. Nesse estágio inicial do desenvolvimento do bebê, a mãe está totalmente ligada aos cuidados do lactante. Esse estado em que se encontram as mães dos recém nascidos é nomeado por Winnicott como sendo "preocupação materna primária". As mães ficam absorvidas e ligadas a seus bebês, tornando-se também dependentes deles. Essa relação próxima entre a mãe e o bebê é essencial para o desenvolvimento da criança. Essa adaptação às necessidades do lactante dura pouco tempo. Nesse estágio de dependência absoluta, o lactante não tem como se conscientizar dos cuidados maternos.

O estágio de dependência relativa começa em torno dos seis meses e vai aproximadamente até os dois anos. Esse período acontece quando o bebê já consegue perceber que é dependente dos cuidados maternos ou de quem exerça a função materna. Quando a mãe se ausenta, por exemplo, e demora para atender à necessidade do filho, já é possível que esse filho utilize seus recursos para suportar a demora da mãe. É importante esclarecer que, caso a mãe se ausente por um período superior à capacidade do bebê em poder acreditar na sua sobrevivência, o bebê será tomado por uma ansiedade. Essa relação 
presença/ausência da mãe e o que isso pode acarretar para a criança, em termos de benefícios ou não, ao seu desenvolvimento emocional, está vinculada à possibilidade que a criança tem de poder suportar uma falha gradual dessa adaptação que vinha ocorrendo.

Simultaneamente a essa percepção que o bebê tem dos cuidados maternos, a mãe sente que seu filho precisa dela, mas que é possível voltar, aos poucos, aos seus interesses anteriores ao nascimento do filho. Aos poucos, a presença paterna é também percebida pelo bebê. Não podemos esquecer que, desde o início, o pai exerce um papel importante, ajudando e dando suporte para que a mãe se adapte às necessidades do bebê. Nesse estágio, o pai não só ajuda a mãe a apresentar o mundo para a criança, como dá suporte para que ela volte para suas atividades.

Quando se fala desse processo inicial e tão fundamental para o desenvolvimento do bebê, no qual a mãe está muito ligada a seu filho, percebe-se que muitos pais se sentem "esquecidos" pela esposa. Um pouco desse esquecimento é próprio do período em que a mãe se encontra. Entretanto, muitos casais sentem dificuldades em retornar à conjugalidade vivida anteriormente à chegada do filho. Para que a criança possa ir desenvolvendo a autonomia a partir das referências vividas na família, é importante que ela viva e perceba que existe um casal que tem um mundo próprio.

Nas novas configurações familiares, onde muitas crianças são educadas por um único adulto, homem ou mulher, também é muito importante que a criança possa perceber que esse adulto, que exerce a função materna, tem seu próprio mundo e que ela está inserida nesse mundo, como alguém importante, mas não como única.

Conforme o processo de dependência/independência vai acontecendo no desenvolvimento infantil, a criança torna-se capaz de se defrontar cada vez mais com o mundo externo, ampliando suas relações e suas experiências. Encontra-se, então, em um novo estágio do desenvolvimento, rumo à independência. Esse estágio, que se inicia aproximadamente aos dois anos, estará presente pelo resto da vida do indivíduo. Como todo processo do desenvolvimento humano, esse processo não é linear, ou seja, há possibilidades de recuo.

\section{A autonomia}

Ao pensar sobre o desenvolvimento da independência no sujeito, é importante abordar o desenvolvimento da autonomia. Pode-se pensar em autonomia fundamentada vários vértices, por exemplo, autonomia financeira, moral, intelectual, entre outras. Neste artigo será abordada a autonomia intelectual, por ser essa a base que possibilita o desenvolvimento das demais possibilidades de um comportamento autônomo. Quando se fala em autonomia intelectual, está-se referindo à possibilidade de se ter um pensamento governado por si próprio, em oposição à heteronomia intelectual, ser governado por outro, submeter-se ao desejo do outro.

No Brasil, o exercício da autonomia é algo ainda a ser construído. Muitos educadores já colocam como um objetivo e meta educacional o desenvolvimento da autonomia. Entretanto, não se pode esquecer a história do nosso país. Há quase sessenta anos atrás, o golpe militar incutiu, entre outras coisas, o medo de se falar e pensar 
autonomamente. Muitos pais foram educados nesse regime de repressão e buscaram alternativas diferentes para educar seus filhos, mas muitas vezes não desenvolveram um pensamento autônomo. O gráfico abaixo representa a relação entre o desenvolvimento da autonomia e da heteronomia.

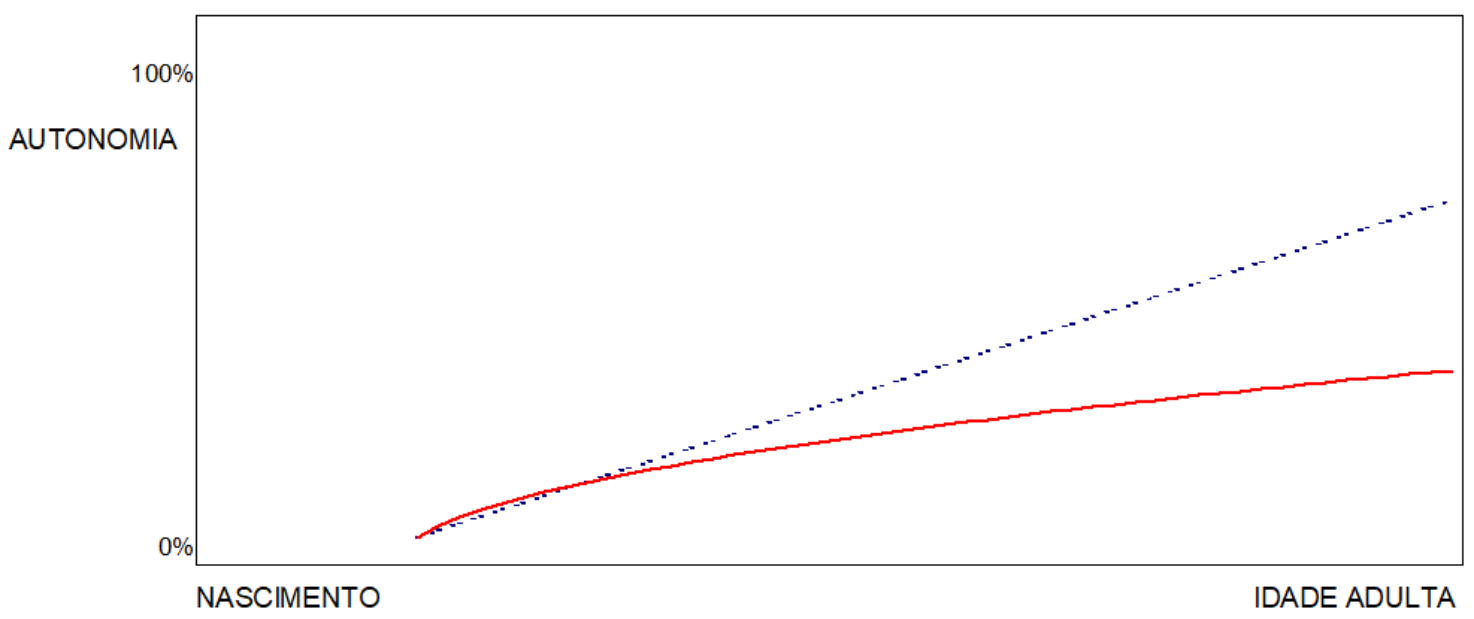

$$
\text { .... Desenvolv imento Ideal Desenvolvimento da maior parte dos adultos }
$$

Fonte: Adaptado de KAMII, C. A criança e o número. Campinas, SP: Papirus, 1986.

\section{Gráfico 1: Relação do Desenvolvimento entre Autonomia e Heteronomia}

O ideal seria que na vida adulta o indivíduo pudesse já ter desenvolvido essa capacidade, mas o que se observa é que muitos adultos não a conquistaram. Observe-se que a linha pontilhada que se refere ao desenvolvimento ideal da autonomia não chega aos $100 \%$, pois não é possível ser totalmente autônomo, como já foi mencionado anteriormente.

Como se daria esse pensamento autônomo no desenvolvimento infantil? Essa forma de pensar surge com a busca, pela criança, de uma referência interna, para resolver as questões que lhe são apresentadas na vida cotidiana. A partir de então, o desenvolvimento dessa forma de pensar só se concretizará à medida que os adultos que com ela convivem puderem ouvir e aceitar tais manifestações. Um exemplo de um pensamento autônomo seria de uma criança de sete anos que não quer ir à missa com os pais. Essa criança pega um giz e risca o chão do quintal: "Missa não!" A mãe tenta convencê-la da importância de ir à missa. A criança argumenta: "- A vida é muito curta para eu perder tempo na missa." A mãe explica que ela só tem sete anos e que viverá muitos anos. A criança, não satisfeita com o argumento da mãe, contrapõe dizendo: "Quem disse que eu não vou morrer atropelada?"

Nesse exemplo mencionado aparece algo importante a ser refletido. Em que medida é possível um membro da família apresentar idéias diferentes dos demais? $\mathrm{O}$ desenvolvimento do pensamento autônomo entre os membros de uma família acontece à medida que a família puder conviver e aceitar as ideias diferentes, a alteridade de cada membro. Muitas famílias sentem dificuldades em conviver com o diferente, pois se 
sentem ameaçadas à medida que seus valores possam ser questionados.

A importância da presença de pais/mães na vida dos filhos é algo inquestionável. Os filhos iniciam a vida por meio de uma dependência absoluta em relação aos seus cuidadores que exercem as funções materna e paterna e vão estabelecendo novas formas de relacionamento ao longo da vida. Os tipos de relação que pais/mães/filhos poderão estabelecer estão vinculados a essas vivências iniciais que foram desenvolvidas.

\section{$O$ adolescente e o adulto jovem}

Devido ao prolongamento da adolescência e à dificuldade de os jovens entrarem no mundo adulto, assumindo responsabilidade e definindo projetos de vida, passou-se a chamar de adulto jovem aquela faixa etária entre o adolescente e o adulto.

A adolescência, enquanto fase do desenvolvimento humano, acabou sendo produzida por nossa cultura. Consegue-se definir quando ela se inicia, mas dificilmente consegue-se dizer quando termina. Esse prolongamento da adolescência também é um produto dos tempos atuais. Mesmo se o adolescente estiver pronto para assumir a vida adulta, pelo menos no aspecto fisiológico, nós, adultos, postergamos esse movimento, deixando para mais tarde. Entretanto, não se consegue saber como ajudá-los a entrar na vida adulta. Surge, então, um novo termo para caracterizar esse adulto jovem, que se diferencia dos demais adultos. O termo jovem na expressão dá uma conotação que ainda não foi possível a entrada por completo na vida adulta.

Antigamente, falava-se que o que diferenciava a adolescência da vida adulta era o trabalho, a entrada no mercado de trabalho. Essa noção, por si só, não dá mais conta de diferenciar o comportamento de um adolescente e o de um adulto. A formação de uma família seria, então, algo que diferenciaria essas duas etapas do desenvolvimento? Possivelmente não, já que, para muitos, casar ou constituir uma família é entendido como uma opção de vida e não sinal de maturidade.

Muitos adultos jovens trabalham e assumem muitas responsabilidades no âmbito profissional. Entretanto, em casa assumem posturas que chamam atenção. Colocam-se como eternos "meninos", não assumindo nenhum tipo de responsabilidade dentro da casa.

Uma possível explicação para essa permanência dos filhos na casa dos pais poderia ser entendida pela comodidade. Alguns pais/mães e filhos justificam que não há razões para que um filho aos trinta anos vá morar sozinho, já que pode continuar na casa dos pais com toda a liberdade. É verdade que, nos dias de hoje, os filhos têm cada vez mais liberdade dentro da casa dos pais. O namoro dentro das casas passou a ser quase um pedido dos pais, que antigamente não viam com bons olhos a permanência de um(a) namorado(a) dormindo na casa.

Tal mudança nos padrões familiares deve-se, principalmente, à violência nas grandes cidades. O número elevado de seqüestros tem confinado e limitado cada vez mais as possíveis experiências e trocas que as crianças e/ou adolescentes poderiam estabelecer na comunidade. A rua passou a ser um lugar visto como perigoso nas grandes cidades, voltando-se a namorar dentro das casas. Entretanto, os filhos passaram a pleitear a possibilidade de terem maior liberdade com seus namorados dentro de casa, reforçando 
sua permanência dentro de casa.

\section{A permanência dos filhos na casa dos pais}

Será, então, que a permanência dos filhos dentro da casa dos seus pais pode ser entendida apenas por comodidade ou facilidade?

A questão que se coloca pode ser entendida por outro vértice. Pode-se pensar, mesmo um filho sendo adulto, que sua saída da casa onde cresceu envolve uma série de questões afetivas. Quando os filhos são adultos, a relação pais/mães/filhos pode estar apoiada em novos parâmetros. É possível estabelecer uma relação de troca muito mais próxima; as conversas já não apresentam um caráter tão assimétrico, em que os pais detêm todo o saber. A hierarquia entre os pais e o filho permanece, mas é possível um contato mais íntimo. Os pais ocupam um novo lugar na vida dos filhos e vice-versa.

A saída da casa dos pais é um corte, uma ruptura, tanto para os filhos como para os pais. Essa separação pode ser vivida com maior ou menor angústia dependendo da família. Algumas famílias não conseguem viver esse luto da separação e os filhos, algumas vezes, mesmo morando em outra casa, fazem de sua casa uma edícula da casa dos pais, permanecendo ao redor da cena da família de origem, não constituindo um espaço de autonomia, separado da casa de seus genitores.

Winnicott (1958) escreveu um artigo intitulado a "Capacidade de estar só". Nesse trabalho, o autor mencionou a possibilidade que o sujeito tem de permanecer só, mas em tranquilidade. Segundo ele, essa possibilidade ou é adquirida no início da vida, ou pode ser desenvolvida por meio de um processo mais sofisticado, após o estabelecimento de relações triádicas. Atualmente, é possível perceber que as pessoas se sentem muito sozinhas e esse estágio do desenvolvimento emocional, de permanecer só, não foi adquirido.

A saída de um filho de casa implica, tanto para os filhos como para o casal parental, a "capacidade de estar só". O casal parental, depois de ter aberto espaço para a chegada do filho, passa a viver novamente uma relação dual. Nessa fase é importante mencionar que o casal já não goza da juventude e muitas vezes a conjugalidade do casal foi se perdendo ao longo dos anos. Nas famílias monoparentais, a dificuldade em sair de casa pode assumir uma intensidade maior se o vínculo entre o adulto e o filho assumiu um caráter de codependência, no qual os dois se apoiam mutuamente e conseguem administrar um projeto de vida desvinculado da presença do outro. Importante mencionar que vínculos de codependência podem existir em qualquer um dos modelos de família acima mencionados, mas se encontra, em algumas famílias monoparentais, com maior intensidade, quando o adulto cuidador tem dificuldade em organizar a própria vida afetiva sem se apoiar na vida afetiva do filho.

Muitos pais/mães sentem dificuldade em ajudar um filho a sair de casa, a assumir os próprios projetos e a cuidar da própria vida, estabelecendo um novo tipo de relação com a família de origem. Essa dificuldade dos pais pode ser entendida pela faixa etária em que eles se encontram, pela dificuldade que eles têm em pensar sobre os projetos que eles têm ou não têm para sua vida e, por fim, em pensar sobre a relação conjugal que 
vivem ou viveram. Muitas vezes se percebe que há um receio por parte dos pais de permanecerem sozinhos.

Em contrapartida, os filhos sentem-se inseguros em administrar a própria vida. Apesar de muitos trabalharem, sentem-se incapazes de ficar só, de se estabelecerem na vida de um modo autônomo. Criados por adultos, muitas vezes, solícitos demais, cresceram com dificuldade em lidar com as próprias frustrações e tentam maquiar a insegurança vivida por eles, justificando a permanência na casa dos pais/mães por comodidade ou por razões econômicas.

Enfim, para entender a permanência prolongada dos filhos na residência dos genitores é preciso analisar o lugar que cada um ocupa na vida do outro. É poder pensar o que significaria para ambos, isto é, tanto para pais/mães como filhos, essa separação. Os cuidadores e filhos podem se separar, à medida que for possível acreditarem que podem estabelecer um novo tipo de vínculo, não nos moldes de um vínculo de dependência mútua, mas de uma troca mais simétrica, em que cada um possa ter seus projetos.

\section{Referências bibliográficas}

KAMII, C. A criança e o número. São Paulo: Papirus, 1986.

MENDONÇA, H. Geração canguru, os jovens que escolheram não sair da casa dos pais. El Pais, 5 de jun. 2017. Disponível em: https://brasil.elpais.com/brasil/2017/06/05/politica/1496687911_980154.html. Acesso em: 20 nov. 2020.

MENDONÇA, M. Mordomias na casa dos pais. Época, São Paulo, n. 332, p.76-82, 27 set. 2004.

WINNICOTT, D. W. A capacidade de estar só. In: WINNICOTT, D. W. (1990) $O$ ambiente e os processos de maturação. Porto Alegre: Artes Médicas, (1958) 1990.

WINNICOTT, D. W. Da dependência à independência no desenvolvimento do indivíduo. In: WINNICOTT, D. W. O ambiente e os processos de Maturação. Porto Alegre: Artes Médicas, (1963) 1990. 